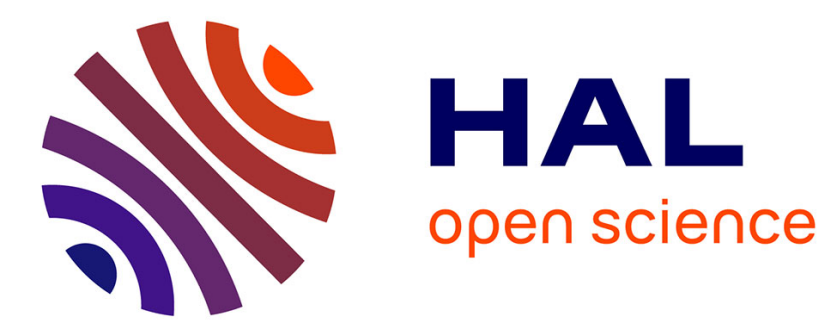

\title{
"Breathing" Motion of a Modulable Molecular Cavity
}

Dawei Zhang, James Robert Cochrane, Sebastiano Di pietro, Laure Guy,

Heinz Gornitzka, Jean-Pierre Dutasta, Alexandre Martinez

\section{To cite this version:}

Dawei Zhang, James Robert Cochrane, Sebastiano Di pietro, Laure Guy, Heinz Gornitzka, et al.. "Breathing" Motion of a Modulable Molecular Cavity. Chemistry - A European Journal, 2017, 23 (27), pp.6495-6498. 10.1002/chem.201700395 . hal-01682791

\section{HAL Id: hal-01682791 \\ https://hal.science/hal-01682791}

Submitted on 14 Apr 2018

HAL is a multi-disciplinary open access archive for the deposit and dissemination of scientific research documents, whether they are published or not. The documents may come from teaching and research institutions in France or abroad, or from public or private research centers.
L'archive ouverte pluridisciplinaire HAL, est destinée au dépôt et à la diffusion de documents scientifiques de niveau recherche, publiés ou non, émanant des établissements d'enseignement et de recherche français ou étrangers, des laboratoires publics ou privés. 


\title{
"Breathing" Motion of a Modulable Molecular Cavity
}

\author{
Dawei Zhang, ${ }^{[a, b]}$ James Robert Cochrane, ${ }^{[b]}$ Sebastiano Di Pietro, ${ }^{[b]}$ Laure Guy, $^{*[b]}$ \\ Heinz Gornitzka, ${ }^{[c]}$ Jean-Pierre Dutasta, ${ }^{[b]}$ and Alexandre Martinez ${ }^{*[b, d]}$
}

\begin{abstract}
A class of hemicryptophane cages that adopt imploded conformations in solution and in the solid state has been described and studied by NMR spectroscopy and X-ray crystallography. It is reported that the degree of collapse of the molecular cavity can be controlled by changing the stereochemistry of the chiral elements of the hemicryptophanes, leading to a modulation of their physical and chemical properties. Upon the binding of an oxidovanadium unit, the collapsed molecular cavity can inflate to give an expanded conformation. Removal of the vanadium core by an ancillary complexing ligand restores the initial folded structure. Thus, coordination/de-coordination of the metal ion controls the dynamic motions of the cage, leading to a reversible nanomechanical process. This controlled motion between a collapsed and expanded cavity can be seen as that of a breathable molecular cage.
\end{abstract}

There is an increased interest in the synthesis and development of systems able to perform a defined function at the molecular level. ${ }^{[1]}$ For instance, molecular machines can produce quasi-mechanical movements (output) in response to specific stimuli (input). Currently, synthetic systems mimicking the abili-

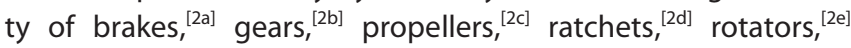
scissors, ${ }^{[2 f]}$ muscles, ${ }^{[2 g, h]}$ gyroscopes, ${ }^{[2]}$ walkers, ${ }^{[2]]}$ and motors ${ }^{[2 k-n]}$

[a] D. Zhang

Shanghai Key Laboratory of Green Chemistry and Chemical Processes School of Chemistry and Molecular Engineering

East China Normal University

3663 North Zhongshan Road, 200062 Shanghai (P. R. China)

[b] D. Zhang, Dr. J. R. Cochrane, Dr. S. Di Pietro, Dr. L. Guy, Dr. J.-P. Dutasta Prof. Dr. A. Martinez

Laboratoire de Chimie

École Normale Supérieure de Lyon, CNRS, UCBL

46 allée d'Italie, 69364 Lyon (France)

E-mail: laure.guy@ens-lyon.fr

[c] Prof. Dr. H. Gornitzka

Laboratoire de Chimie de Coordination

CNRS, 205 Route de Narbonne, BP 44099

Université de Toulouse, UPS, INPT

31077 Toulouse, Cedex 4 (France)

[d] Prof. Dr. A. Martinez

Aix Marseille Univ, CNRS

Centrale Marseille, iSm2, Marseille (France)

E-mail: alexandre.martinez@centrale-marseille.fr have been widely devised and studied. Among them, catenanes and rotaxanes are well known molecular systems that are frequently used as supramolecular forces in the design of molecular devices. ${ }^{[1, k]}$ Remarkable molecular motion of molecular strands from folding to unfolding states has also been achieved using coordination/de-coordination of metal ions. ${ }^{[3]}$

Recently, besides the properties of recognition, catalysis, and reactive species stabilization, there has been growing interest in molecular cages in the construction of molecular machines. ${ }^{[4]}$ For instance, hemicryptophanes have been used to achieve nanomechanical processes mimicking the function of gyroscopes or molecular propellers. ${ }^{[2,4]}$ Although nice examples of size and shape modifications of molecular cavities in self-assembled or covalent cages have been recently described ${ }^{[5]}$ control of the dynamic motion in molecular cages from fully folded to extended states is still a challenge.

We previously reported the synthesis of a new family of enantiopure hemicryptophane cages bearing three types of stereogenic elements, that is, helical, axial, and central chirality, which result from the cyclotriveratrylene (CTV), binaphthol, and trialkanolamine moieties, respectively, giving rise to four pairs of enantiomers (Figure $1 \mathrm{a}$ ). ${ }^{[6]}$ Here, we report how these chiral units modulate the shape and size of the inner cavity and the consequences on their physical and chemical properties. We found that these molecular cages collapse in solution and that the resulting imploded form can re-inflate upon the complexation of an oxidovanadium unit. This conformational change between the collapsed and expanded form is reversible, leading to a synthetic molecule simulating the breathing motion upon the binding-unbinding of an external stimulus.

Crystals of $M-R R R-R R R-1 \cdot 2\left(\mathrm{CHCl}_{3}\right) \cdot 0.5\left(\mathrm{Et}_{2} \mathrm{O}\right)$ suitable for X-ray diffraction analysis were obtained by slow evaporation from a concentrated solution of the cage in $\mathrm{CHCl}_{3} / \mathrm{Et}_{2} \mathrm{O}$. The structure of hemicryptophane $M-R R R-R R R-1$ exhibits a $C_{3}$ symmetry with an unexpected imploded conformation where the trialkanolamine core is collapsed within the CTV unit obstructing the inner cavity (Figure 2 and Figure S1 in the Supporting Information). ${ }^{[7]}$ The three $\mathrm{OH}$ groups point outward, forming hydrogen bonds with the two closest $\mathrm{O}$ atoms of the binaphthol groups (O...O distances, 2.77-2.94 $\AA$ ), whereas the $\mathrm{NCH}_{2}$ protons, directed toward the CTV unit, interact with the aromatic rings (distances between the axial proton of $\mathrm{NCH}_{2}$ and the closest CTV aromatic ring, 3.08-3.53 $\AA$ ).

Insights into the conformations of the cavities of the four diastereomers of 1 in solution were obtained by ${ }^{1} \mathrm{H} N M R$, ${ }^{13} \mathrm{C}$ NMR, COSY, HSQC, and HMBC experiments (see the Supporting Information). In the ${ }^{1} \mathrm{H} N M R$ spectra, we can observe the high-field shifted signals of the $\mathrm{NCH}_{2}$ protons (Figure 1 and 


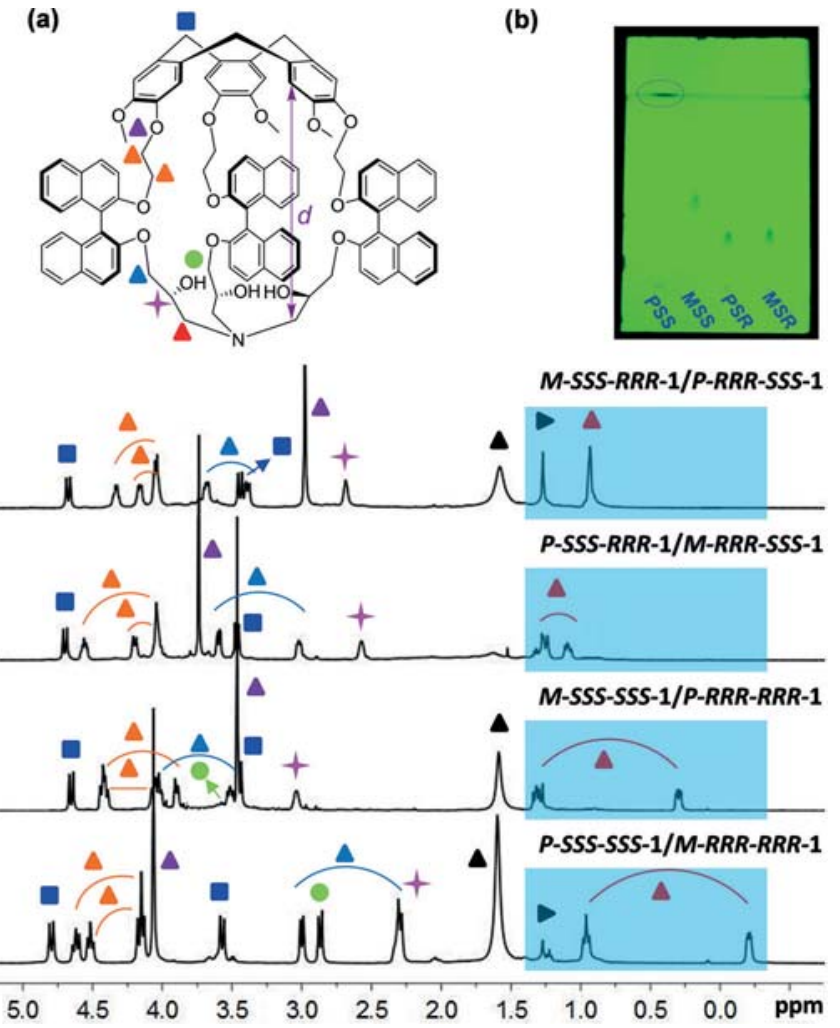

Figure 1. (a) Partial ${ }^{1} \mathrm{H}$ NMR spectra $(500.1 \mathrm{MHz}, 298 \mathrm{~K})$ of the four diastereomeric pairs of hemicryptophane 1 in $\mathrm{CDCl}_{3}$ and their protons assignment. $\boldsymbol{\Delta}=$ water; $\boldsymbol{\nabla}=$ grease. The high-field shifted $\mathrm{NCH}_{2}$ protons are highlighted. The distance $d$ between the more shielded $\mathrm{NCH}_{2}$ proton and its closest CTV aromatic- $\mathrm{H}$ has been illustrated, which is used for the evaluation of the cage collapse degree. (b) TLC migration properties of 1 (silica, eluent: $\mathrm{CH}_{2} \mathrm{Cl}_{2}$ / $\mathrm{MeOH}=200 / 3$ ); the symbols used are the abbreviation names of each hemicryptophane isomers, for instance, PSS represents P-SSS-SSS-1.
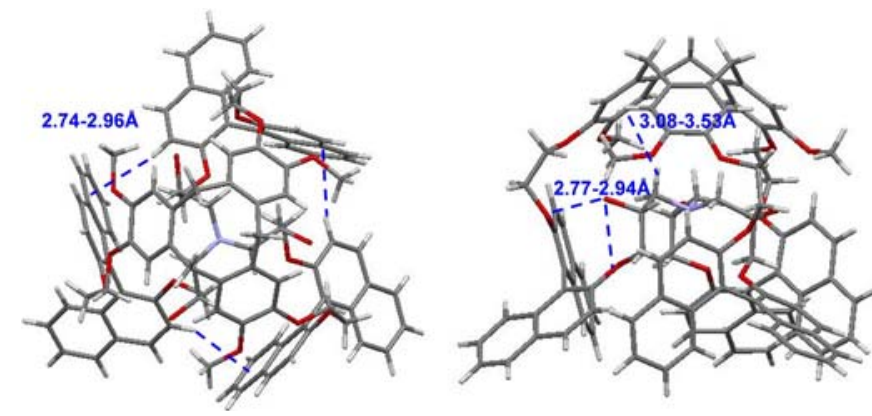

Figure 2. Crystal structure of $M-R R R-R R R-1$. Solvent molecules are omitted for clarity. Dashed lines in the left figure represent the distance between the two neighboring binaphthyl groups, and those in the right figure represent the distances between the axial proton on $\mathrm{NCH}_{2}$ and its closest aromatic- $\mathrm{H}$ on $\mathrm{CTV}$ or between the $\mathrm{O}$ atom on $\mathrm{OH}$ and its two closest binaphthyl $\mathrm{O}$ atoms.

Figure S2 in the Supporting Information), with a shielding order P-SSS-SSS-1 $(\delta=-0.20 \mathrm{ppm})>$ M-SSS-SSS-1 $(0.30 \mathrm{ppm})>$ $M$-SSS-RRR-1 $(0.97 \mathrm{ppm}) \approx P$-SSS-RRR-1 (1.08 ppm). These highfield shifted signals are consistent with imploded conformations, as viewed in the crystal structure (Figure 2). To further demonstrate the concave conformation of each cage in solution, ROESY experiments were performed (Figures S3-S6 in the
Supporting Information). Cross-peaks between the protons of the trialkanolamine core and the aromatic and methoxy protons of the CTV unit directly evidence short distances between the two moieties $(<5 \AA)$ and are indicative of the imploded conformations of these host molecules in solution. The interproton distance between the most shielded $\mathrm{NCH}_{2}$ proton and its closest CTV aromatic-H (see Figure $1 \mathrm{a}$ and the Supporting Information) was calculated, giving a distance for P-SSS-SSS-1/ $M-R R R-R R R-1$ in the range of $3.03-3.08 \AA$, in agreement with that measured from the crystal structure (3.08-3.53 $\AA$ ). Moreover, the implosion degree indicated by the calculated $\mathrm{H} \cdots \mathrm{H}$ distances for each cage follows the same trend as that of the chemical shifts of the shielded $\mathrm{NCH}_{2}$ protons: P-SSS-SSS-1 (average: $3.06 \AA)>M$-SSS-SSS-1 (3.21 $\AA$ ) > P-SSS-RRR-1 (3.86 $\AA$ ). The measurement for M-SSS-RRR-1 failed due to peak overlap of the two $\mathrm{NCH}_{2}$ signals. These results suggest that the size and shape of the cavity can be modulated by the chirality of its constitutive chiral units. Notably, this imploded conformation is also retained in other solvents such as $\left[D_{8}\right]$ toluene and $\left[D_{6}\right]$ DMSO, and at higher temperatures (up to $373 \mathrm{~K}$, Figures S7 and $\mathrm{S} 8$ in the Supporting Information).

Several physical properties of these cages are directly related to the hierarchical modulation in the size and shape of their inner cavities. With the increase of the implosion degree from M-SSS-RRR-1 to P-SSS-SSS-1, (i) the ${ }^{1} \mathrm{H}$ NMR signal of the alcohol proton becomes sharper and sharper (Figure $1 \mathrm{a}$ ), (ii) their exchange with MeOD becomes increasingly difficult (Figure S9 in the Supporting Information), and (iii) the migration properties of these compounds on TLC plates appears easier $\left(R_{\mathrm{f}}\right.$ equals $1.00,0.47,0.29$, and 0.30 for P-SSS-SSS-1, M-SSS-SSS-1, P-SSS$R R R-1$, and M-SSS-RRR-1, respectively, Figure $1 \mathrm{~b}$ ). All these observations indicate that the alkanolamine core of the most imploded cage P-SSS-SSS-1, which occupies the inner cavity, is well protected by the CTV shelter, significantly reducing its interaction with the surrounding environment.

Coordination/de-coordination of metal ions can allow for dynamic motions and reversible nanomechanical processes of molecular compounds; ${ }^{[3]}$ we thus prepared the oxidovanadium(V)-1 hemicryptophane complexes, which were also developed as efficient oxidation catalysts recently. ${ }^{[8]}$ The reaction of each cage diastereomer with 1.0 equiv of vanadium $(\mathrm{V})$ reagent was carried out at room temperature in $\mathrm{CDCl}_{3}$ and monitored by ${ }^{1} \mathrm{H}$ NMR (Figures S10 and S11 in the Supporting Information). Interestingly, it was found that the reaction rate with the most imploded cage P-SSS-SSS-1 was ten-fold slower than those of the other three diastereomers, suggesting a higher energy barrier for the reorganization of the structure for vanadium complexation. In addition, in the ${ }^{1} \mathrm{H}$ NMR spectrum of the vanadium@P-SSS-SSS-1 complex in $\mathrm{CDCl}_{3}$, the chemical shifts of the $\mathrm{NCH}_{2}$ protons are in the region of $1.28-1.78 \mathrm{ppm}$ (Figure S12). Compared to those of the free ligand $(-0.20$ and $0.95 \mathrm{ppm})$, these protons show an obvious down-field shift. ROESY experiments performed on this complex reveal no NOE correlation between the trialkanolamine unit and the CTV moiety (Figure S13). These results are in agreement with strong conformational changes leading to the inflation of the molecular cavity through vanadium complexation (Figure 3). 


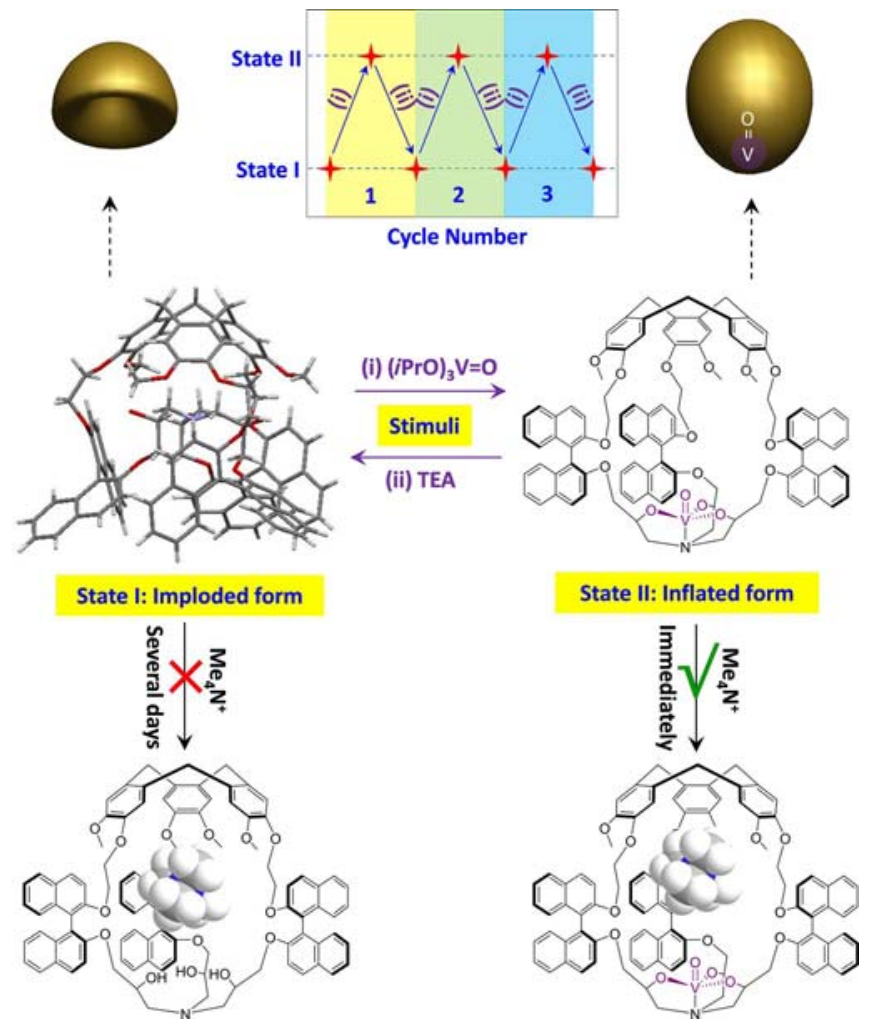

Figure 3. Graphical representation of the hemicryptophane cage switching between its bi-stable states, that is, imploded and inflated conformations, with external inputs. This switching can be done for at least three cycles. The new inflated vanadium complex is able to further encapsulate the ammonium guest, whereas the parent imploded ligand cannot.

Furthermore, tetramethyl ammonium $\left(\mathrm{Me}_{4} \mathrm{~N}^{+}\right)$can be efficiently bound by the vanadium@M-SSS-RRR-1 cage with a binding constant of $547 \mathrm{M}^{-1}$ (Figure S14), ${ }^{[8]}$ evidencing the presence of a well-defined cavity in the complex. An MM3 model of vanadium@M-SSS-RRR-1 with $\mathrm{Me}_{4} \mathrm{~N}^{+}$encapsulated inside the cavity was prepared using SCIGRESS software (Figure S15). ${ }^{[9]}$ Results show that the distance $d$ between the more shielded $\mathrm{NCH}_{2}$ proton and its closest CTV aromatic- $\mathrm{H}$, as indicated in Figure 1, has been expanded from 3.86 to $13.57 \AA$. In contrast, when similar experiments were performed with $\mathrm{Me}_{4} \mathrm{~N}^{+}$and any of the free molecular hosts 1 , no characteristic complex-induced shift of the $\mathrm{Me}_{4} \mathrm{~N}^{+}$signal was observed, even after several days. These results demonstrate that the inner cavity of the vanadium cage complex is accessible, whereas there is no available molecular cavity in the parent free host. Thus, it seems clear that the vanadium acts as an inflator to fully inflate the imploded cages.

To test the reversibility of the inflation-deflation dynamic process, we studied the binding-unbinding properties of the hemicryptophanes 1 with vanadium(V) oxytriisopropoxide. To remove the oxidovanadium moiety from the cage ligand, an excess of triethanolamine (TEA) was added to a solution of vanadium@M-SSS-SSS-1 in $\mathrm{CDCl}_{3}$. The NMR spectrum showed that vanadium was fully de-coordinated from the cage ligand, followed by immediate collapse, proving that the imploded structure of the free ligand is much more stable than its globu- lar form. Subsequent addition to this solution of an excess of vanadium(V) oxytriisopropoxide recovered the initial shape of the vanadium@hemicryptophane complex. This switch between the imploded and inflated bi-stable states has been performed at least for three cycles in the case of M-SSS-RRR-1 (Figures 3 and Figure S16 in the Supporting Information). Therefore, through the input of vanadium reagent or TEA as a stimulus, the hemicryptophane cage can artificially "breathe".

In summary, we have described herein a class of imploded hemicryptophane cages. The level of collapse, which can be indicated by the interproton distances between the CTV and trialkanolamine units, have been measured, based on NOE crosspeaks of the ROESY spectra. It was found that the imploded degree of the cages can be controlled by varying the stereochemistry of the constructing units. Stereomodulation of the inner cavity also results in the regulation of their corresponding physical and chemical properties. For instance, the reaction between vanadium(V) oxytriisopropoxide and the most imploded cage P-SSS-SSS-1 suffers from a slower reaction rate compared to the other three diastereomers. Interestingly, vanadium complexation re-inflates the cage from its imploded conformation to a globular form, and the resulting vanadium core can also be removed from the inner cavity according to external coordination with TEA. Thus, this system is capable of switching between the imploded and expanded bi-stable states through external inputs, leading to a molecular breathing motion. This class of molecular cage has, for the first time, been exploited as a novel mode of switching, which is worth exploring further for potential applications.

\section{Acknowledgements}

A.M. would like to thank ANR OH-risque for funding, grant number: ANR-14-OHRI-0015-01.

[1] a) V. Balzani, A. Credi, F. M. Raymo, J. F. Stoddart, Angew. Chem. Int. Ed. 2000, 39, 3348-3391; Angew. Chem. 2000, 112, 3484-3530; b) S. ErbasCakmak, D. A. Leigh, C. T. McTernan, A. L. Nussbaumer, Chem. Rev. 2015, 115, $10081-10206$; c) C. J. Bruns, J. F. Stoddart, Acc. Chem. Res. 2014, 47, 2186-2199; d) E. C. Harvey, B. L. Feringa, J. G. Vos, W. R. Browne, M. T. Pryce, Coord. Chem. Rev. 2015, 282, 77-86; e) J. W. Canary, Chem. Soc. Rev. 2009, 38, 747-756; f) C. A. Schalley, K. Beizai, F. Vögtle, Acc. Chem. Res. 2001, 34, 465-476; g) E. R. Kay, D. A. Leigh, F. Zerbetto, Angew. Chem. Int. Ed. 2007, 46, 72-191; Angew. Chem. 2007, 119, 72-196; h) J. H. Jordan, B. C. Gibb, Chem. Soc. Rev. 2015, 44, 547-585; i) R. Kay, D. A. Leigh, Angew. Chem. Int. Ed. 2015, 54, 10080-10088; Angew. Chem. 2015, 127, 10218-10226; j) J.-C. Chambron, J.-P. Sauvage, New J. Chem. 2013, 37, 49-57; k) J.-P. Sauvage, C. Dietrich-Buchecker, Molecular Catenanes, Rotaxanes and Knots: A Journey through the World of Molecular Topology Wiley-VCH, Weinheim, 1999; I) W. Wang, Y.-X. Wang, H.-B. Yang, Chem. Soc. Rev. 2016, 45, 2656-2693. 
[2] a) B. E. Dial, P. J. Pellechia, M. D. Smith, K. D. Shimizu, J. Am. Chem. Soc. 2012, 134, 3675-3678; b) Y. Tian, C. D. Mao, J. Am. Chem. Soc. 2004, 126 $11410-11411$; c) A. Martinez, L. Guy, J.-P. Dutasta, J. Am. Chem. Soc. 2010 132, 16733-16734; d) T. R. Kelly, I. Tellitu, J. P. Sestelo, Angew. Chem. Int. Ed. Engl. 1997, 36, 1866-1868; Angew. Chem. 1997, 109, 1969-1972; e) M. Hughs, M. Jimenez, S. Khan, M. A. Garcia-Garibay, J. Org. Chem. 2013, 78, 5293-5302; f) T. Muraoka, K. Kinbara, Y. Kobayashi, T. Aida, J. Am. Chem. Soc. 2003, 125, 5612-5613; g) M. C. Jiménez, C. Dietrich-Buchecker, J.-P. Sauvage, Angew. Chem. Int. Ed. 2000, 39, 3284-3287; Angew. Chem. 2000, 112, 3422-3425; h) Y. Liu, A. H. Flood, P. A. Bonvallett, S. A. Vignon, B. H. Northrop, H.-R. Tseng, J. O. Jeppesen, T. J. Huang, B. Brough, M. Baller, S. Magonov, S. D. Solares, W. A. Goddard, C.-M. Ho, J. F. Stoddart, J. Am. Chem. Soc. 2005, 127, 9745-9759; i) T. Shima, F. Hampel, J. Gladysz, Angew. Chem. Int. Ed. 2004, 43, 5537-5540; Angew. Chem. 2004, 116, 5653-5656; j) M. J. Barrell, A. G. Campana, M. von Delius, E. M. Geertsema, D. A. Leigh, Angew. Chem. Int. Ed. 2011, 50, $285-$ 290; Angew. Chem. 2011, 123, 299-304; k) P. Kovaricek, J.-M. Lehn, Chem. Eur. J. 2015, 21, 9380-9384; I) L. Greb, J.-M. Lehn, J. Am. Chem. Soc. 2014, 136, 13114-13117; m) N. Koumura, R. W. J. Zijlstra, R. A. van Delden, N. Harada, B. L. Feringa, Nature 1999, 401, 152-155; n) T.-C. Lee, M. Alarcon-Correa, C. Miksch, K. Hahn, J. G. Gibbs, P. Fischer, Nano Lett. 2014, 14, 2407-2412.

[3] M. Barboiu, A.-M. Stadler, J.-M. Lehn, Angew. Chem. Int. Ed. 2016, 55, 4130-4154; Angew. Chem. 2016, 128, 4200-4225.

[4] a) D. Ajami, L. Liu, J. Rebek, Jr., Chem. Soc. Rev. 2015, 44, 490-499; b) K. I. Assaf, W. M. Nau, Chem. Soc. Rev. 2015, 44, 394-418; c) S. Zarra, D. M. Wood, D. A. Roberts, J. R. Nitschke, Chem. Soc. Rev. 2015, 44, 419-432; d) K. Kobayashi, M. Yamanaka, Chem. Soc. Rev. 2015, 44, 449-466; e) C. J.
Brown, F. D. Toste, R. G. Bergman, K. N. Raymond, Chem. Rev. 2015, 115, 3012-3035; f) M. Raynal, P. Ballester, A. Vidal-Ferran, P. W. van Leeuwen Chem. Soc. Rev. 2014, 43, 1660-1733; g) M. Yoshizawa, J. K. Klosterman, M. Fujita, Angew. Chem. Int. Ed. 2009, 48, 3418-3438; Angew. Chem. 2009, 121, 3470-3490; h) T. Brotin, J.-P. Dutasta, Chem. Rev. 2009, 109, $88-130$; i) N. S. Khan, J. M. Perez-Aguilar, T. Kaufmann, P. A. Hill, O. Taratula, O.-S. Lee, P. J. Carroll, J. G. Saven, I. J. Dmochowski, J. Org. Chem. 2011 76, 1418-1424.

[5] a) S. Wang, T. Sawada, K. Ohara, K. Yamaguchi, M. Fujita, Angew. Chem. Int. Ed. 2016, 55, 9704-9708; Angew. Chem. 2016, 128, 9856-9860; b) F. A. Arroyave, P. Ballester, J. Org. Chem. 2015, 80, 10866-10873.

[6] D. Zhang, J.-C. Mulatier, J. R. Cochrane, L. Guy, G. Gao, J.-P. Dutasta, A. Martinez, Chem. Eur. J. 2016, 22, 8038-8042.

[7] a) O. Taratula, P. A. Hill, N. S. Khan, P. J. Carroll, I. J. Dmochowski, Nat Commun. 2010, 1, 148; b) S. T. Mough, J. C. Goeltz, K. T. Holman, Angew. Chem. Int. Ed. 2004, 43, 5631-5635; Angew. Chem. 2004, 116, 5749 5753 ; c) G. Huber, T. Brotin, L. Dubois, H. Desvaux, J.-P. Dutasta, P. Berthault, J. Am. Chem. Soc. 2006, 128, 6239-6246.

[8] D. Zhang, K. Jamieson, L. Guy, G. Gao, J.-P. Dutasta, A. Martinez, Chem. Sci. 2017, 8, 789-794.

[9] M. Kieffer, B. S. Pilgrim, T. K. Ronson, D. A. Roberts, M. Aleksanyan, J. R. Nitschke, J. Am. Chem. Soc. 2016, 138, 6813-6821. 